\title{
Ser Artista-Ator-Humano na Relação com o Objeto Técnico: Possíveis Diálogos Entre É. Decroux e G. Simondon
}

Não se representa, engendra-se e percorre-se.

(Deleuze e Guattari, 1997, p. 25)

O artificial é o natural suscitado.

(Simondon, 2008, p.256)

\section{Resumo}

O texto discute possíveis relações entre a arte de Étienne Decroux e o pensamento filosófico de Gilbert Simondon, apresentando um diálogo sobre homem e máquina em seus modos de existência e relações.

PALAVRAS-CHAVE: Étienne Decroux; Gilbert Simondon; Homem-máquina.

\section{Abstract}

The paper discusses possible relations between the art of Étienne Decroux and philosophical thought of Gilbert Simondon, presenting a dialogue on man and machine in their modes of existence and relationships.

KEYWORDS: Étienne Decroux; Gilbert Simondon; Man-machine.

1 Bya Braga é nome artístico de Maria Beatriz Mendonça. Artista cênica. Doutora em Artes Cênicas pela UNIRIO-RJ. Professora Adjunta do Departamento de Fotografia, Teatro e Cinema da Escola de Belas Artes, Universidade Federal de Minas Gerais (UFMG), exercendo ali atividades de ensino e pesquisa junto ao Curso de Teatro e Programa de Pós-Graduação em Artes, com ênfase nas questões da atuação, do teatro de movimento e da pesquisa prática. Coordena o LAPA-Laboratório de atuação: pesquisa prática artística, da UFMG. Coordena o Grupo de Trabalho Territórios e Fronteiras da Associação Brasileira de Pesquisa e Pós-Graduação em Artes Cênicas-ABRACE. Autora do livro Étienne Decroux e a artesania de ator: caminhadas para a soberania, no prelo pela Editora da UFMG. 
Como o artista-ator-humano se torna o que se é? Ser ou não ser? Ser e ser outro? Como ser? Imitar a máquina? Como é possível ser ator na relação com um objeto técni$c o$ ? Ser ator-mimo e homem-máquina? $\mathrm{Ou}$, ainda, como o indivíduo ator se torna o que se é e o que ele poderá ser neste século XXI?

Estas são questões que motivam a existência deste texto por perpassarem as atividades de pesquisa cênica que realizo. Não considero perguntas fáceis, mas se tornaram uma inquietação constante para mim. Penso sobre elas propondo, aqui, uma conversa, não a resolução de problemas, e a inicio, especialmente, trazendo fragmentos de minha vivência com a arte inventiva de Étienne Decroux (1898-1991), denominada por ele Mímica Corporal Dramática, somando a ela uma pequena experiência de leitura e estudo de textos do filósofo Gilbert Simondon (1924-1989).

Quando cito, no título deste texto, a expressão objeto técnico, esclareço que me inspiro no que Simondon diz sobre o tema, ou seja, um objeto técnico não é somente uma coisa ou outra coisa em estado de concretização (termo usado pelo filósofo), mas aquilo no qual há uma gênese. Pode-se perceber aqui uma preocupação em fundamentar seu pensamento por meio, também, de teorias biológicas. Pensar uma concepção genética do objeto técnico, acompanhar como uma fase pode gerar outra, é sua opção de método para estudar o ato de fazer algo no mundo. A gênese humana lhe serve de inspiração, bem como as operações técnicas geradas por meio de seus gestos como, por exemplo, a fabricação de objetos primitivos como a ponta da flecha formada da lasca de uma pedra forjada pelo homem.

Os objetos técnicos são gerados de operações técnicas e se concretizam no mundo como seres diversos. Todos se apresentam por meio de uma produção, um ato de fazer, mas inseridos no movimento do mundo e em relação com todos os outros seres deste mundo.

Simondon se preocupava em explicar que um objeto técnico se concretiza gradativamente orientado pelo princípio genético da tecnicidade, mesmo que for- jado inicialmente pela intervenção de um operador e vindo a se constituir como um sistema relativamente autônomo de causalidades recíprocas, ou seja, um objeto que possui agenciamento próprio. Mas para ele, além do objeto técnico ser este sistema relativamente autônomo, também atende à realização de certa finalidade para sua existência. Eis um ponto importante para o diálogo aqui proposto: o sentido de finalidade relacionado à funcionalidade.

A máquina é um objeto técnico que "funciona" entre processos de forma e informação, segundo o filósofo. Mas, na sua visão, esta funcionalidade se apresenta para além das questões da divisão capitalista do trabalho, ou seja, não se pretende permanecer restrita a um caráter utilitário de atendimento à dominação humana e suas necessidades. Este "funcionamento" diz respeito aos mecanismos que a máquina apresenta e que corporificam um processo criativo, uma dinâmica de existência, iniciada na sua concretização como objeto já no pensamento de seu inventor. A máquina funciona porque é pensamento que se transformou em uma forma "funcionante". Mesmo possuindo previsibilidades de ação em seus mecanismos, ela não está inapta para sofrer variações seja por intermédio da interferência humana, ou não. Isto é, ela pode não se reduzir ao que comumente seria compreendido como automatismo, mas, surpreendentemente, se apresentar com certa margem de indeterminação ao seu funcionamento. O "robô cientista", já conhecido hoje na ciência, pode sinalizar o que digo aqui, de um ponto de vista tecnológico. ${ }^{2}$ Este objeto técnico específico pode ser compreendido hoje para além da visão do autômato, de um artefato mecânico, podendo inclusive passar por processos de adaptação ao meio! Quem sabe, até, mudando sua natureza!

O vocabulário aqui usado pode causar estranhamento. Mas ele está diretamente relacionado ao léxico de Simondon. O utilizo, portanto, a fim de falar sobre como o

2

Refiro-me aqui à experiência de criação do "robô cientista" relatada no artigo "Rise of the Robo Scientists Machines can devise a hypothesis, carry out experiments to test it and assess results-without human intervention", de Ross D. King. 
objeto técnico envolve, dentro da perspectiva exposta pelo filósofo, uma preocupação com a otimização da relação entre fim e meio, em perspectiva diferencial do modo de produção capitalista, e também para considerar que a máquina existe, neste sentido, como um ser que, em sua mediação técnica, submete-se a critérios de eficácia funcional. Insisto: na minha compreensão, esta noção de "eficácia funcional" não se restringe às questões de resolução de problemas. Neste sentido, oponho-me ao que pode ainda ser entendido para o sentido de existência de um objeto artístico com uma noção de utilidade de resolução de problemas entre o homem e seu meio. Mesmo considerando sua existência objetual, em modo estético, que revele explicitamente a apresentação de um modo de fazer ou uma corporificação de algo, um objeto estético não precisa "carregar" com ele o sentido de "reparar" algo no mundo, ou de "aparar" as desigualdades que existem entre o homem e seu ambiente, o que pode ser esperado de um objeto técnico. $\mathrm{O}$ objeto estético, para aqui criar diálogos com o objeto técnico proposto por Simondon, pode escapar dessa percepção de "reparação". A noção de objeto técnico apresentada pelo filósofo pode dialogar com a arte se pensamos neste objeto em termos, especialmente, do processo de sua concretização, de sua corporificação, valorizando também o momento de desenvolvimento da sua própria existência objetual como um tempo contínuo, que não se acaba. Trata-se aqui de pensar em um processo de individuação, ou melhor, uma operação de individuação que o artista também vive.

No caso do ator, em especial aquele que trabalha explicitamente com o manuseio técnico corpóreo de si, considerando esse processo como mecanismo de contrafação de seu corpo, o que é o caso da técnica Mímica Corporal Dramática de Étienne Decroux, há uma operação de individuação que me parece evidente, ainda que em outros processos ela também possa existir. O indivíduo pré-constituído é problematizado, artisticamente, sendo considerado uma "realidade relativa" e em relação com o meio. O limite do corpo, seu espaço no mundo, é colocado em estado de jogo de dilatação. O mimo-ator é um "ator dilatado", para Decroux (Decroux, 1994: 66). Na conquista desta dilatação, tecnicamente, há uma diretriz de trabalho que mexe com a individualidade dos corpos nas interarticulações feitas em si mesmo, no contato consigo mesmo que esta arte propicia como revisão do ser. O corpo do mimo-ator se multiplica como em uma visão de um objeto na arte cubista em razão de sua multiplicidade, de sua dilatação que não é, simplesmente, um aumento de massa, uma forma relativa ao espaço que ocupa. Trata-se de um estado de ser e estar no mundo que se torna apto a estabelecer conexões com o meio e, por isso, também a se modificar enquanto estrutura. O mimo-ator parece disponível e em estado de atenção ampliada para estar em contínua formatação, plena de dinamorritmos e rítmicas outras, para além do espaço que modela, em um processo contínuo de fabricação de si, de individuação. Com a arte mímica corporal, problematiza-se de modo singular a origem técnica do humano, ou seja, sua gênese. Esta arte não parece existir, tecnicamente, somente para "reparar" a relação do artista-ator com o mundo, como pode ser pensada primordialmente a relação do homem com um objeto técnico que conhecemos como máquina. Possivelmente a arte mímica corporal existe, também, ou até primordialmente, para que o humano seja e que esteja aberto para conexões diferentes com o meio.

Nesta perspectiva, a arte cênica realizada e transmitida por Decroux se revela como um espaço de excelência para experimentar a realidade relativa do ser, de um existir diferenciado que se relaciona com um pré-existir. Ela contribui para que $\mathrm{o}$ ator pense o humano no mundo não somente como um reparador de desigualdades de modos de existência neste mundo, mas como um criador, um inventor de problemas, um ser que se apresenta e que está em presença. A Mímica Corporal Dramática pode, neste sentido, colaborar com o ator de modo singular em um processo de experiência vital, entre padrões de ação artís- 
tica que se repetem e se diferenciam.

Simondon é um pensador que discutiu a crise da humanidade na relação com a máquina, com o mundo técnico, com os objetos técnicos. A máquina, para ele, é um ser que concretiza um funcionamento diretamente relacionado a uma dinâmica de pensamento humano anterior a ela. É esta dinâmica de pensamento que gera sua invenção objetual e produz funcionamentos. Quando a máquina funciona, porém, ela passa por variações. Isso, para Simondon, me parece importante pois é um modo de expor um "retrato" do pensamento e do processo criativo ali instalado, ou seja, existente na própria maquinação. Sim, há um processo criativo vivo ali no objeto técnico e, ainda, segundo o filósofo, que demonstra possuir um gesto humano depositado nele. A ciência, aqui, possui relação singular com a técnica e com o próprio processo de humanização, de individuação, tomando ainda a referência do léxico simondoniano.

A fala de Simondon sobre este modo de existência do objeto técnico me chama a atenção para pensar o objeto artísti$\mathrm{co}$, entendendo-se aqui objeto como algo que se concretiza, corporifica, que é fruto de uma experiência laboratorial, uma artesania. $\mathrm{O}$ objeto não é simplesmente um artefato, compreendido de modo restrito e marcado pelo materialismo mecanicista-reducionista. A artesania, bem como seus possíveis objetos gerados, também não deveria mais ser vista como um fazer que está limitado às exigências do objeto criado, ou seja, separada do pensamento e submetida somente às leis mecânicas antigas, sem levar em consideração as singularidades evidenciadas no seu processo de existir. Pensar o fazer artesão deste modo restrito é um preconceito de origem filosófica também. A artesania é mais que o atendimento à finalidade utilitária e servil de concretização de algo. Ela pode exalar um processo relacional. $\mathrm{O}$ artesão pode ser também um inventor, um mediador de inovações. Neste sentido, o ator-mimo, o que realiza formatações, também se formata na relação com o mundo. É, portanto, um ator artesão.
O artesão será, pois, definido como aquele que está determinado a seguir um fluxo de matéria, um phylum maquínico. É o itinerante, o ambulante. Seguir o fluxo de matéria é itinerar, é ambular. É a intuição em ato. (Deleuze e Guattari, 1997, p. 79)

Quando conheci alguns estudos simondonianos publicados atraí-me pela sua preocupação quanto à gênese do indivíduo pensada, ao mesmo tempo, entre pesquisas e comentários a respeito da máquina e da técnica. Isso me levou a pensar que poderia haver em suas investigações também um traço de "ciência nômade", como a conceituariam Deleuze e Guattari quando dizem sobre procedimentos científicos que consistem em "seguir" em vez de "reproduzir" algo. Para eles, o procedimento científico do "seguir" é a maneira de se distanciar de um ponto de vista fixo sobre algum pensamento, experimento, podendo fluir em conexões singulares como, por exemplo, pensar a relação do humano com a máquina sem que esta se reduza, especialmente, à sua finalidade utilitária em seu uso pelo homem, ou seja, distanciando-a da imagem maquínica do mundo natural, em noção tomada de uma ideia sobre a inflexibilidade de procedimentos de reprodução de objetos.

[...] seguir é coisa diferente do ideal de reprodução. Não melhor, porém outra coisa. Somos de fato forçados a seguir quando estamos à procura das "singularidades" de uma matéria ou, de preferência, de um material, e não tentando descobrir uma forma; quando escapamos à força gravitacional para entrar num campo de celeridade; quando paramos de contemplar o escoamento de um fluxo laminar com direção determinada, e somos arrastados por um fluxo turbilhonar; quando nos engajamos na variação contínua das variáveis, em vez de extrair dela constantes, etc. E não é em absoluto o mesmo sentido da Terra: segundo o modelo legal, não paramos de nos reterritorializar num ponto de vista, 
num domínio, segundo um conjunto de relações constantes; mas, segundo o modelo ambulante, é o processo de desterritorialização que constitui e estende o próprio território. (Deleuze e Guattari, 1997, p. 34).

A busca de diálogo que faço entre Simondon e Decroux se inspira, então, na ressonância de um "desvio", uma tentativa "variante" de pensamento sobre as proposições por eles apresentadas.

Étienne Decroux inventou, além da técnica mímica corporal, várias peças correspondentes a ela. Destaco aqui a parte de uma peça, apresentada para Gordon Craig, em 1945, em uma apresentação pública, que deveria integrar sua Evocação das ações concretas (Leabhart, 2007, p. 15) e que era constituída de três momentos. Um deles era denominado A máquina, que foi composta a partir de estudos de observação relacionados ao tema, oriundos de procedimentos aprendidos na escola de Jacques Copeau, mas que se pretendia ser uma experiência cênica que transcendesse a representação de um objeto e pudesse mostrá-lo ao modo de uma transposição artística não realista. Esta peça $A$ máquina foi anterior à criação de Decroux denominada A fábrica, de 1946, mais conhecida e com registro em vídeo, na qual podem ser observados estudos de contrapeso mímico corporal entre outros elementos de sua técnica de atuação. A peça $A$ máquina buscava "evocar as ações concretas" maquínicas de origem em interligações corporais singulares. Segundo Thomas Leabhart, A máquina deixava transparecer elementos subjetivos relacionados às artes gráficas, ao teatro, ao cinema, à dança e à mímica antiga, evidenciando traços da arte futurista. Na expressão artística futurista, segundo ele enfatiza, as artes buscavam tematizar a questão da relação do artista com os mecanismos. De fato, a imagem maquínica foi bastante utilizada desde o século XVIII como metáfora do comportamento do mundo, fortalecendo uma concepção mecanicista da vida e as artes puderam também falar sobre isso. Mas a máquina mudou.
Decroux considerava, nos anos sessenta, "idiota" o comportamento maquínico para servir de referência ao corpo do mimo-ator, pois "segundo o corpo, a máquina é um monstro" (Decroux, 1994: 106). ${ }^{3}$ Ela não possui, segundo o artista, o que nós conhecemos, não possui, antes de tudo, as proporções entre força e peso que possuímos, nem entre a rapidez de deslocamento de um membro e sua resistência, bem como sua rapidez de inclinação. Máquina, neste sentido, está impregnada da imagem maquínica clássica e, assim, não é percebida nela a possibilidade, ao menos em "traços", de uma natureza complexa como é o sistema humano. Para Decroux, a mímica corporal

[...] não pode tomá-la [a máquina] como modelo. E não se inspirará em imitar a reação a uma emoção brusca, pois isso é um ato barato de produção. Ao contrário, a máquina se torna um modelo a imitar porque é o oposto a esse trabalho de força e da reação contendo uma emoção brusca. Mudando o ritmo e a força, nos inspiramos na máquina para atuar: a indiferença, o desdém, a majestuosidade, a sabedoria serena, o domínio, o determinismo, a lei, a justiça, o dever, a lógica, o paraíso. Quer dizer, tudo o que exclui: a luta do homem contra a matéria, ou o problema do livre arbítrio. Com outros ritmos e forças temos: o hábito, o cômico, a loucura. (Decroux, 1994: 106-107).

Mesmo que a noção predominante sobre a máquina no pensamento de Decroux sinalize, neste momento, uma ideia maquínica clássica, ela também parecer indicar uma referência de procedimento técnico que ele valoriza e que o ajuda a relatar sobre sua arte. Ele fala na "encarnação da geometria móvel"; e o problema da "geometria móvel" corpórea, para Decroux, é revelado quando o público descobre algo que o mimo-ator não queria fazer e pergunta o que é que o ator quis fazer de fato,

3 As traduções aqui realizadas são de minha autoria e diretamente feitas do original francês, com revisão de Marco Diniz. 
ou seja, o público não vê precisão das ações artísticas, sistematização do movimento cênico no corpo do ator. Se é para fazer algo, do ponto de vista de Decroux, isso deve ser "feito de propósito" pelo ator. Para ele, "a linha tem o direito de suicidar-se, não de morrer" (DECROUX, 1994: 108). O "fazer de propósito" traz a noção de maquinidade que pode se concretizar de modo mais complexo, ampliado para além da questão mecanicista-reducionista que ele tinha objeção.

No capítulo quarto do livro deste artista, Paroles sur le mime, cujo título é "Mímica e mímica", há uma parte que trata da "Primazia do corpo sobre rosto e braços" (é preciso entender aqui a referência ao "corpo" como a parte do "tronco" humano). Neste momento Decroux ator-autor fala da "exatidão geométrica" que percebe ser necessária ao ator. Ele pergunta, explicitamente, "para que serve imitar uma máquina?". Diz o artista:

Assim é o braço: semelhante a um bailarino perdido no fundo do palco que sai do grupo e se adianta para mostrar a nós o que sabe ou o que não sabe fazer. [...] Nosso braço não é de todo favorecido. Pagará por não ser pesado e nem perigoso de cair. É sua ligeireza que o impede, exatamente, de saber onde está. [...] Em sua vez, faz o possível, todo o possível... Seus erros serão escandalosos. [...] Não vejo que o rosto tenha condições tão severas de trabalho." (Decroux, 1994: 109-110).

Proponho pensar aqui a noção de imitação falada por ele como criação em transposição do real, como maquinação artística que pode gerar objetos estéticos singulares e que não necessariamente se pareçam com as referências de origem. Outras perguntas são feitas pelo artista cênico: o que é a harmonia? Uma criação? "Não estou seguro", diz Decroux; a harmonia entre os órgãos do mimo, em atuação, pode ser "uma ciência, uma matemática subconsciente. Que nos Estados Unidos digam 'balance' e eu 'soli- dariedade interorgânica' confirma essa presunção" (Decroux, 1994: 110). Não necessariamente, para Decroux, a harmonia do humano implica em criação proposital sempre, considerando que também há harmonia no movimento que faz no cotidiano, no "natural' do ser humano, que pode existir no ato de alongamento de um corpo, no caminhar de um passante, ações que possuem outros modos técnicos corporais. Decroux conjectura sobre a possibilidade de nós termos, um dia, perdido a harmonia e pergunta se o encanto com o mecanismo da máquina não poderia trazê-la de volta. Neste sentido, harmonia pode ser criação proposital, ou seja, o propósito em tornar a arte visível poderia contar com um procedimento maquínico como referência, ao modo da concretização de um objeto técnico que exige precisão na articulação de grande parte de seus mecanismos. Mas Decroux pensa a máquina de modo a parecer localizá-la em uma noção redutora. Por isso, afirma que a máquina não é um fator de harmonia porque ela elimina algumas vias de seu acesso, ou seja, ela elimina o homem com a consciência plena de si e de seu trabalho consigo mesmo. Aqui Decroux parece indicar um paradoxo que não é um paradoxo. É possível a precisão e a organicidade juntas em uma experiência técnica artística. Mas, para o artista, a máquina também elimina a surpresa. Neste caso, ele reduz a imagem da máquina somente à noção mesma de seus mecanismos.

Mas, ao pensar o objeto técnico e a máquina com Simondon, a maquinação pode também se abrir-se para surpresas. Parece-me curioso, ao ver o trabalho de Decroux, que a prática de sua pesquisa pareça estar muito além do que ele consegue produzir textualmente para falar dela. Por outro lado, suas questões me parecem atuais. A prática da maquinação, da formatação, da contrafação do corpo em sua arte é algo que entendo como além da noção redutora da máquina que se apresenta, por vezes, em sua fala. Existem outras questões também que podem influenciar seu modo de ex- 
posição do tema, como a necessidade que lhe é imposta, quase, socialmente, no território da profissionalização artística, em separar sua invenção da dança. Ele foi acusado de plágio, em copiar a dança, o que o preocupou porque se concentrava em seu caminho de invenção e não negava suas influências. Em relação à dança ele realmente quis se distinguir dela.

É ainda neste momento do livro de Decroux, sobre a harmonia, que ele faz uma crítica às condições de vida social e ao trabalho no modo capitalista de produção. Eu poderia, aqui, pensar também em Simondon por este demonstrar possuir objeção ao modelo social (capitalista) do trabalho que enfatizava a subordinação da e na operação tecnológica. Ou seja, esta, em si, não é uma opressão e não deveria ser vista de modo redutor. A operação tecnológica não representa alienação para o filósofo. Mas a apropriação que o trabalho no modo capitalista faz dela, sim.

Decroux apresenta outro comentário que me parece instigante também trazêlo aqui. Entre seu forte olhar crítico contra o capitalismo em modos de produção industrial e, paralelamente, a observação de si em seu processo humano de envelhecimento, ele revela, aos sessenta e quatro anos, sua percepção do corpo como algo que está se "endurecendo". "Escapará o artesão dessa condição? Não acredito, porque dizer ofício é reconhecer a especialidade" (Decroux, 1994: 113). Ele cita, então, uma de suas categorias de jogo de atuação como alternativa para dizer deste momento singular em que o corpo humano se apresenta "fixando-se" em alguns padrões de movimento: "Eis aqui o 'homme de peine"', que é aquele que carrega o mundo, que está curvado por carregar o mundo. “ $\mathrm{E}$ esse homem que se move evoca uma tortura vertical. O que me faz pensar que se a máquina não sabe converter-se em uma causa de harmonia, sua ausência é causa de desarmonia" (Decroux, 1994: 113). (Grifos meus). Para Decroux, "custa trabalho obter do aprendiz comum essa harmonia". Por isso, o procedimento maquínico é algo a se valorizar. Assim,
Tudo está permitido na arte, desde que seja feito de propósito. E já que na nossa arte o corpo do homem é a matéria, é necessário que seja ele [o corpo] que imite o pensamento. Como o mármore, a cor, o ar, o corpo é obra antes que se faça uma obra com ele, o que significa apesar dele. Sua forma diz sua função. Sua forma não muda. O corpo do homem está condenado a se parecer um corpo de homem. Requer que se contrafaça em seus movimentos. Como o material que se utiliza em outras artes, 0 corpo é sensível, necessita que sofra e se contrafaça. Senão, o corpo imita exclusivamente o corpo. (Decroux, 1994: 114).

Contrafazer é, portanto, um modo singular de maquinar, parecendo por vezes insólito, um procedimento de corporificação em uma dada perspectiva artística, mas que não precisa segregar o objeto técnico, mesmo como referência. Tomá-lo em seu modo de existência como inspiração procedimental pode ser uma experiência que colabora para a individuação do ser humano-artista-ator.

Simondon abordou em seus estudos temas diversos, não se restringindo a ser, portanto, um "pensador da técnica" ou "da máquina". Ele abordou questões sobre a física do cristal, a biologia dos parasitas, psicologia das emoções e da percepção, ética, artesania, técnica, cibernética, entre outros, defendendo o uso de noções científicas para o estudo filosófico. Para Simondon, o ser vivente existe no mundo não somente em estado de adaptação, mas ele vive modificando-se a si mesmo, criando estruturas diferentes que o movimentam nesta relação. Para o filósofo existe um "subconsciente" em um ser que é afetivo-emotivo, criado na relação com o outro e com o ambiente. A auto-modulação que o indivíduo faz para criar a si mesmo, integra um modo de existência em sua individuação que é uma experiência processual.

Seguir este raciocínio nos leva, portanto, a pensar o humano de modo não tão coerente ou desejável mais. Isso já 
pode ter ficado evidente aqui ao leitor. Mas destaco que Simondon elabora, por exemplo, um modo de pensar o humano, o ser vivente, em relação ao que é artificial, aproximando a humanidade da máquina. Ele abre de modo explícito a possibilidade de pensarmos o homemmáquina, mas sem uma noção redutora da própria máquina. Ele propõe uma diluição de oposições e dicotomias feitas na relação entre matéria, vida e pensamento. Decroux parece fazer isso na prática de sua arte de ator. Mas é preciso praticála a fim de se perceber isso. E querer praticá-la sem percebê-la como, por exemplo, Jacques Lecoq a percebeu, ou seja, de modo redutor. Christophe Merlant, na ocasião em que escreveu um artigo sobre Jacques Lecoq, afirmou que este possuía muita admiração por Étienne Decroux, mas que desde o momento em que o viu pela primeira vez ele compreendeu que não poderia ser seu aprendiz (Gourdon, 2004, p. 67). O argumento de Lecoq para tal afirmação é que Decroux realizava um modo de arte mímica que gerava nele uma sensação de arte formalista, com ênfase no esteticismo, podendo entender seu comentário relacionado também à imagem maquínica clássica, antiga. Lecoq se equivocou? Possivelmente sim se pensarmos que Decroux exerceu continuamente suas pesquisas práticas durante décadas e que em cada momento ele se concentrava em pesquisas distintas. $\mathrm{Ou}$ seja, Decroux não criou uma arte formalista e a visão do "esteticismo" dita por Lecoq me parece limitada. Mas é fato que esta compreensão é possível de existir em razão, por exemplo, da difícil difusão de sua arte, ou mesmo da finalidade que o artista pretendia com ela, isto é, um teatro de atitude e não um teatro de gesto.

Para Simondon, a máquina pode e deve resolver problemas da adaptação do humano no mundo, mas uma interação com ela necessita reconhecer a possibilidade de mudança de estruturas em ambos. Decroux pode ser contrário à visão maquínica clássica como modelo de sua arte, mas indaga, por outro lado, sobre o procedimen- to maquínico que possa gerar "harmonia", o feito de propósito. O processo de individuação para Simondon possui um aspecto amplo, tanto no físico quanto no biológico, no psíquico e no social, porque foca na processualidade, descarta a perspectiva de dar forma ou moldar algo e opta pelas ideias de modulação continuada. Decroux, a seu modo, exalta sua arte como arte da presença do ator, da atitude do artista, e não necessariamente arte da forma que tem como sentido de existência somente uma relação com o espaço ou ilustração do meio ao seu redor. Ele propõe uma relação com o tempo em sua arte e não somente com o espaço. Para Simondon, é preciso experimentar modular como um ato de moldar de modo contínuo e sempre variável. Neste caso, o indivíduo não recebe uma forma para existir. Ele se auto-modula, sempre.

Pensar com esta perspectiva, em profundidade, pode ser desesperador para quem olha o humano totalmente fora de uma sensação maquínica, ou mesmo materialista, corpórea, ou seja, quem compreende a máquina como oposto ao "natural", considerando-a somente mecanismo distinto da vida. Simondon nos ensina que ela não é só isso. Para ele, a vida é uma dinâmica de operações, de corporeidades em processualidades.

Simondon, ao contrário de R. Descartes, não é afeito às dicotomias. Ele se oporia a Decroux quando esse diz que a máquina é “filha da Razão" (Decroux, 1994: 105), ainda que se compreenda o contexto em que o artista age para expor suas ideias desta maneira. Decroux quer evidenciar a máquina no contexto capitalista de produção, vista como um objeto relacionado à dominação na medida em que, especialmente, atende a sobrevivência do homem, sua necessidade de dominação das forças da natureza e outros seres. O homem faz da máquina um ser dominado por ele, sua propriedade, para explorar dela sua função utilitária que atenderia sua demanda. Ou seja, a máquina "filha da Razão" tende a ser vista como uma simbolização de uma razão corporificada oriunda da tecnociência que propaga relações servis entre os seres, revela uma 
relação de trabalho pautada na exploração. Sua peça A fábrica mostra isso.

O ser humano, sendo entendido como uma entre várias outras formas de existência, na qual o objeto técnico é uma delas, deve ser compreendido em seu modo de ser como um ato de criação. Ser e ser outro, continuamente. Uma criação de si, a partir de uma forma de operação e processualidade, aliando-se a isso, no caso do mimo-ator, a percepção sobre seu potencial de dilatação corpórea, de ampliação na relação consigo e com seu meio.

Decroux pensou o mimo-ator como um ser dilatado cuja percepção em relação ao mundo se apresentaria de modo singular e ampliado a partir do trabalho do ator sobre si mesmo, especialmente por meio de um exercício técnico artístico específico. Ou seja, algo que ele pudesse experimentar e que lhe fosse "estrangeiro" ao seu comportamento "natural", fosse um artifício para a potencialização do processo criativo presente nele como ser em criação constante, vindo a existir como processo-resultado artístico. Nominando sua arte como "prometeica", Decroux também sinalizou seu desejo de criar um entre lugar entre deuses e homens para o ator.

Portanto, sinto que posso me deparar, constantemente, com terremotos epistêmicos ao estudar a relação homem-máquina, ao pesquisar a arte de Decroux e me aproximar, também, do pensamento de Simondon. Continuo não vendo possibilidade de conforto para pensar sobre o caráter maquínico do ser humano, o sentido disso hoje na arte cênica. Mas percebo a possibilidade de uma compreensão ampliada sobre as aproximações entre sujeito e objeto, podendo criar, concretamente, outras formatações para o humano. Isso me instiga, pois permite pensar no aparecimento da união da criatura (humana ou não) com o artefato, neste caso considerado como algo separado do ser humano, o que me parece importante para as questões surgidas nos processos criativos cênicos tratados seja na revisão da tradição teatral com Decroux, seja por Gordon Craig, por exemplo, ou mesmo na arte atual em invenções que contemplam interlinguagens e relações explícitas com a tecnologia visível.

A proposta de individuação trazida por Simondon, uma realização processual, em vez de ser algo já dado no humano, sinaliza para o fato de que o indivíduo não foi criado semelhantemente à moldagem de algo que nada era anteriormente e que, ao se aplicar um molde sobre uma superfície adequada, forjou-se "a coisa" nela. Há um teatro da individuação, expressão do filósofo. O corpo humano também é um artefato que suscita o natural. 


\section{REFERENNCIAS}

DECROUX, Étienne. Paroles sur le mime. Paris: Librairie Théâtrale, 1994.

DELEUZE, G. e GUATTARI, F. Mil platôs: Capitalismo e esquizofrenia. Trad. Peter Pál Pelbart e Janice Caiafa. V. 5. São Paulo: Ed. 34, 1997.

FLEMING, McClung. Artifact Study: a proposed model. In: Thomas J. Schlereth (org). Material Culture Studies in America. Walnut Creek, California: Altamira Press, 1999. p. 162173.

GOURDON, Anne-Marie (org). Les nouvelles formations de l'interprète. Théâtre, danse, cirque, marionnettes. Paris: CNRS Éditions, 2004.

KING, Ross D. Rise of the Robo Scientists Machines can devise a hypothesis, carry out experiments to test it and assess results - without human intervention. Disponível em: http://www. scientificamerican.com/article.cfm?id=rise-of-the-robo-scientists.

ScientificAmerican.com, January 2011, p. 73 a 77, acesso em 21/5/2012, 10h.

LEABHART, Thomas. Étienne Decroux. New York: Routledge, 2007.

NOVAES, A. (Org.). Homem-máquina: a ciência manipula o corpo. São Paulo: Cia. das Letras, 2003.

ROUX Jacques. Saisir l'être em son milieu Voyage em allagma tique simononienne. In: Simondon, Pascal Chabot (Org.), Paris: Librairie Philosophique J. Vrin, 2002, p. 121-135.

SIMONDON, G.. El modo de existencia de los objetos técnicos. Buenos Aires: Prometeo, 2008. La individuación a la luz de las nociones de forma e información. Buenos Aires, Ediciones la Cebra y Editorial Cactus, 2009.

L'individu et sa genèse physico-biologique. Paris: Presses Universitaires de France, 1964.

STENGERS, Isabelle. A invenção das ciências modernas. São Paulo: Editora 34, 2002.

VACCARI, Andrés. Vida, técnica y naturaleza en el pensamiento de Gilbert Simondon. Revista CTS, $n^{\circ} 14$, vol. 5, Mayo de 2010, p. 153-165. 